\title{
ARTICLES
}

\section{Status and threats to vultures in China}

\author{
Roller MaMing* and Guohua Xu
}

Xinjiang Institute of Ecology and Geography, Chinese Academy of Sciences, No. 818 Beijing Road, Urumqi, 830011, Xinjiang, P. R. of China.

*Corresponding author: maming3211@yahoo.com

http://dx.doi.org/10.4314/vulnew.v68i1.1

\section{Introduction}

Populations of three old world vulture species, Gyps bengalensis, Gyps tenuirostris and Gyps indicus collapsed across the Indian Subcontinent (Prakash et al. 2012). These population declines were attributed to the use of a nonsteroidal anti-inflammatory drug, diclofenac, that causes visceral gout subsequently leading to renal failure in vultures that consume carcasses contaminated with the drug (Green $e t$ al. 2004, Oaks et al. 2004, Naidoo et al. 2009). This situation raised concerns about their lesser-known relatives and the survival of vultures has cultural as well as ecological implications. Despite extensive studies on these three species, little is known about population trends in highland areas, particularly in China, where there have been few studies of the large carrion-eating raptors. Currently, there is little information available regarding the use of veterinary diclofenac for livestock in western China, and little is known about populations and dynamics of vultures in China overall (Pain et al. 2003, Lu et al. 2009, Ma et al. 
2013). Therefore, in this paper we want to introduce background information regarding vultures and their protection status in China.

Vultures include 16 living species that occur on the Old World. However, in China there are more vultures species than most other countries (eight species), accounting for $50 \%$ of vulture species in the Old World. They are Bearded Vulture (Gypaetus barbatus), White-rumped Vulture (Gyps bengalensis), Himalayan Griffon (Gyps himalayensis), Eurasian Griffon (Gyps fulvus), Cinereous Vulture (Aegypius monachus), Red-headed Vulture (Sarcogyps calvus), Slenderbilled Vulture (Gyps tenuirostris) and Egyptian Vulture (Neophron percnopterus) respectively (Zhang \& Yang 1980, Gu et al. 1994, Zheng 2011, Guo and Ma 2012). The species have an extensive geographical distribution, centred on the northwest, the Tibetan plateau, Pamir plateau and the southwest minority areas in China. Meanwhile, the Tibetan plateau has been regarded as the kingdom of vultures
(Di 2003), because there are more than seven Old World Vulture species distributed there (Ma et al. 2014). At the same time, nearly 28 million people live on the Tibetan Plateau. Some vultures depend predominantly on livestock carcasses as food resources and this highlights their ecological importance in the highland ecosystem. Meanwhile, human corpses also provide a small fraction of the total food resource to vultures, so the vultures play a unique role in the centuries-old sky burial tradition followed by Tibetan people. In short, vultures have not only ecological but also cultural value. Therefore, extra attention should be directed at the conservation of these scavenging species.

Distribution and Population of Vultures in China

The vultures of China have received great attention from the government. The dramatic population crashes of three species of Gyps vulture in the south Asia was a good example and 
urged China to take some measures to protect these species. In 1988, the Law of the People's Republic of China on the Protection of Wildlife established two categories of nationally protected wild animals, and most species in these two categories are rare and threatened. In 2001, the State Forestry Administration announced an additional list of nationally protected species that are either beneficial or with important economic or scientific value. This list covered an additional 707 species of birds, including many that are common and widespread in China. In addition to the nationally protected species, many provinces have published lists of locally protected wildlife.

Under these laws, there is some effective protection for the listed wildlife. For example, in August 2002, the defendants Li Yuesheng, Li Congrong and Li Ziqi caught 26 Himalayan Griffons in a nature reserve of Yunnan Province, and all the vultures died in the end, so they were sentenced to 10 years, 12 years and 13 years respectively and fined by the court according to the wild animal conservation law. On May 20, 2013, Lei was arrested for mailing a Cinereous Vulture skeleton illegally, and was sentenced by the court.

Despite protection efforts such as these, most vulture populations are still in a downward trend over recent years. Table 1 presents data on eight vulture species in China and the world, summarised from government websites, the State Forestry Administration, BirdLife International and the IUCN Red List of Threatened Species.

Based on recent investigations (Ma 2011), only three vultures are common in China: Gyps himalayensis, Gypaetus barbatus, and Aegypius monachus. The numbers of other vulture species, such as Egyptian Vulture and Slender-billed Vulture, are small and mostly only recorded one to three times in the past 50 years. According to data released by the State Forestry Administration in 2009, the population size of the Bearded Vulture was estimated at 92,000 
individuals in China (e.g. 22,018 in on population data and the Xinjiang, 32,500 in Qinghai, 29,126 distribution area described by in Gansu, 7,500 in Xizang [Tibet], BirdLife (2014) and the IUCN Red 800 in Sichuan, 54 in other parts of List, we estimated the number of the China) (National Forestry Bureau 2009). However, this species breeds at low densities in other parts of its range and in some other countries there are only 200-300 pairs in total. Furthermore, the global population of the Bearded Vulture is estimated to be less than 10,000 individuals. Therefore, there is some doubt over the accuracy of data provided by the Chinese Forestry Bureau about the population size of the Bearded Vulture; as a result, we re-calculated the population estimate again. Based

eight vulture species in China according to their distribution and population size in the world (Table 1). The eight vulture species distributed in China are mainly in the western regions of the country $(\mathrm{Xu}$ 1995, Ma 2011, Zheng 2011). Figure 1 shows the distribution of these species and highlights that most species are centered on the Tibetan Plateau. Ranges also extend into the southwest, northwest, Inner Mongolia (Kenny et al. 2008) and the Himalaya. 
Table 1: Summary of status, numbers, distribution of Old World Vultures and key threats to vultures in China

\begin{tabular}{|c|c|c|c|c|c|}
\hline Species & $\begin{array}{l}\text { Distribution } \\
\text { (summary) }\end{array}$ & $\begin{array}{c}\text { Global } \\
\text { population } \\
\text { (individuals) } \\
\end{array}$ & $\begin{array}{c}\text { Global } \\
\text { distribution } \\
\left(\mathrm{km}^{2}\right) \\
\end{array}$ & $\begin{array}{c}\text { Current } \\
\text { trend }\end{array}$ & $\begin{array}{l}\text { Red List } \\
\text { Status* }\end{array}$ \\
\hline $\begin{array}{l}\text { Bearded Vulture } \\
\text { (Gypaetus barbatus) }\end{array}$ & $\begin{array}{l}\text { Bhutan, China, India, Mongolia, Pakistan, } \\
\text { Russia, Central Asia, Middle East, Europe, } \\
\text { North East and East Africa }\end{array}$ & $2,000-10,000$ & $8,840,000$ & Decreasing & $\mathrm{LC}$ \\
\hline $\begin{array}{l}\text { White-rumped Vulture } \\
\text { (Gyps bengalensis) }\end{array}$ & $\begin{array}{c}\text { Bangladesh, Bhutan, China, India, Myanmar, } \\
\text { Pakistan, South-East Asia }\end{array}$ & $3,500-15,000$ & $4,920,000$ & Decreasing & CR \\
\hline $\begin{array}{c}\text { Eurasian Griffon } \\
\text { (Gyps fulvus) }\end{array}$ & $\begin{array}{c}\text { Central Asia, Europe, North Africa, Turkey, } \\
\text { China }\end{array}$ & $40,000-50,000$ & $10,200,000$ & Increasing & LC \\
\hline $\begin{array}{l}\text { Cinereous Vulture } \\
\text { (Aegypius monachus) }\end{array}$ & $\begin{array}{c}\text { Bhutan, China, India, Myanmar, Pakistan, } \\
\text { Mongolia, East Asia, Central Asia, Middle } \\
\text { East, Europe } \\
\end{array}$ & $21,000-30,000$ & $13,700,000$ & Decreasing & NT \\
\hline $\begin{array}{l}\text { Slender-billed Vulture } \\
\text { (Gyps tenuirostris) }\end{array}$ & Bangladesh, India, Myanmar, South-East Asia & $1,500-3,750$ & 847,000 & Decreasing & NT \\
\hline $\begin{array}{c}\text { Egyptian Vulture } \\
\text { (Neophron } \\
\text { percnopterus) } \\
\end{array}$ & $\begin{array}{l}\text { India, Pakistan, China, Central Asia, Africa, } \\
\text { Europe (more southerly countries), Middle East }\end{array}$ & $20,000-61,000$ & $18,700,000$ & Decreasing & EN \\
\hline
\end{tabular}

* Critically Endangered (CR), Endangered (EN), Near Threatened (NT), and Least Concern (LC). Global population estimates from BirdLife (2014) and IUCN Red List (2013). Population size in China estimates were based on the world population and distribution area. 
Table 1: continued.

\begin{tabular}{|c|c|c|c|c|c|}
\hline Species & $\begin{array}{l}\text { List in } \\
\text { China }\end{array}$ & Distribution in China & $\begin{array}{l}\text { Est. China } \\
\text { population }\end{array}$ & Chief threats & Research needs \\
\hline $\begin{array}{l}\text { Bearded } \\
\text { Vulture }\end{array}$ & I & $\begin{array}{l}\text { Shanxi, Inner Mongolia, Tibet, } \\
\text { Xinjiang, Qinghai, Ningxia, NW } \\
\text { Yunnan, Western Sichuan, Hubei, } \\
\text { Hebei, Shaanxi }\end{array}$ & $\begin{array}{l}6,900- \\
9,900\end{array}$ & $\begin{array}{c}\text { Poisoning, persecution, } \\
\text { habitat loss, disturbance, } \\
\text { power lines, windfarms, } \\
\text { lack of safe food }\end{array}$ & $\begin{array}{l}\text { Monitoring population, food } \\
\text { habits, breeding ecology }\end{array}$ \\
\hline $\begin{array}{l}\text { White-rumped } \\
\text { Vulture }\end{array}$ & I & The western and SW of Yunnan & $100-200$ & $\begin{array}{l}\text { NSAID poisoning, lack of } \\
\text { safe food }\end{array}$ & $\begin{array}{l}\text { NSAIDs, monitoring } \\
\text { population, breeding }\end{array}$ \\
\hline $\begin{array}{l}\text { Himalayan } \\
\text { Griffon }\end{array}$ & II & $\begin{array}{l}\text { Xinjiang, Gansu, Qinghai, Tibet, } \\
\text { Ningxia, Sichuan, Western Yunnan }\end{array}$ & $\begin{array}{l}90,000- \\
230,000\end{array}$ & $\begin{array}{l}\text { NSAID poisoning, lack of } \\
\text { safe food }\end{array}$ & $\begin{array}{c}\text { NSAIDs, monitoring } \\
\text { population, food habits, } \\
\text { breeding }\end{array}$ \\
\hline $\begin{array}{c}\text { Eurasian } \\
\text { Griffon }\end{array}$ & II & Western Xinjiang, SE Tibet & $100-300$ & $\begin{array}{l}\text { Persecution, poisoning, lack } \\
\text { of safe food, power lines }\end{array}$ & $\begin{array}{l}\text { Monitoring population, food } \\
\text { habits, breeding }\end{array}$ \\
\hline $\begin{array}{l}\text { Cinereous } \\
\text { Vulture }\end{array}$ & II & $\begin{array}{c}\text { Xinjiang, Qinghai, Gansu, Ningxia, } \\
\text { Mongolia, Shanxi, Sichuan. } \\
\text { Tibet, SE China, Taiwan } \\
\end{array}$ & $\begin{array}{l}9,000- \\
15,000\end{array}$ & $\begin{array}{c}\text { Disturbance, lack of safe } \\
\text { food, poisoning, secondary } \\
\text { poisoning (NSAIDs) }\end{array}$ & $\begin{array}{c}\text { NSAIDs, monitoring } \\
\text { population, food habits, } \\
\text { breeding }\end{array}$ \\
\hline $\begin{array}{l}\text { Red-headed } \\
\text { Vulture }\end{array}$ & II & SW Yunnan, SE Tibet & $100-300$ & $\begin{array}{l}\text { Persecution, secondary } \\
\text { poisoning, lack of safe food, } \\
\text { intensification of agriculture }\end{array}$ & $\begin{array}{l}\text { NSAIDs, monitoring } \\
\text { population, food habits, } \\
\text { breeding }\end{array}$ \\
\hline $\begin{array}{l}\text { Slender-billed } \\
\text { Vulture }\end{array}$ & II & SE Tibet & $20-100$ & $\begin{array}{l}\text { NSAID poisoning, lack of } \\
\text { safe food }\end{array}$ & $\begin{array}{c}\text { NSAIDs, monitoring } \\
\text { population, food habits, } \\
\text { breeding }\end{array}$ \\
\hline $\begin{array}{l}\text { Egyptian } \\
\text { Vulture }\end{array}$ & II & Western Xinjiang & $20-100$ & $\begin{array}{c}\text { Disturbance, poisoning, } \\
\text { electrocution, food } \\
\text { availability } \\
\end{array}$ & $\begin{array}{l}\text { Monitoring population, food } \\
\text { habits, breeding }\end{array}$ \\
\hline
\end{tabular}


Figure 1: Distribution maps of the eight vulture species in China

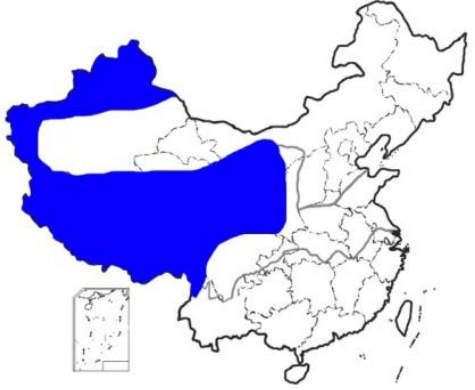

Bearded Vulture

(Gypaetus barbatus)

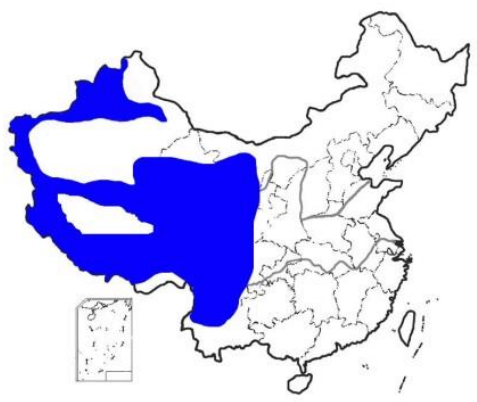

Himalayan Griffon

(Gyps himalayensis)

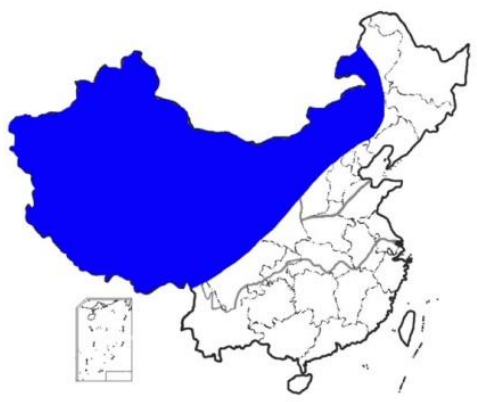

Cinereous Vulture

(Aegypius monachus)

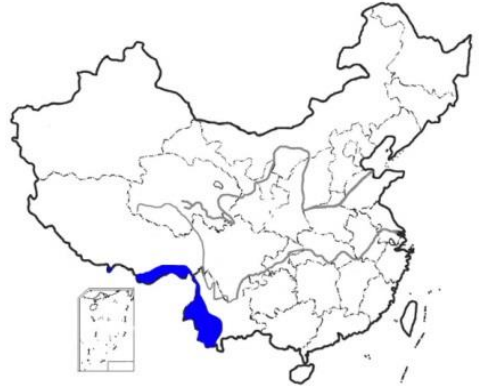

White-rumped Vulture

(Gyps bengalensis)

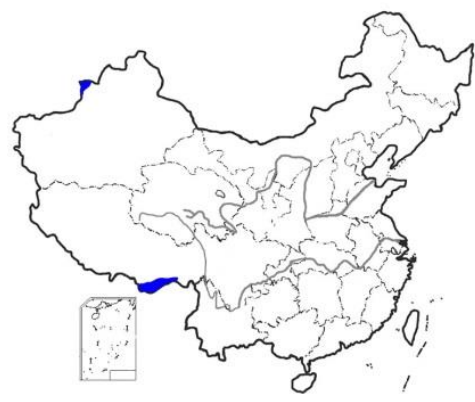

Eurasian Griffon

(Gyps fulvus)

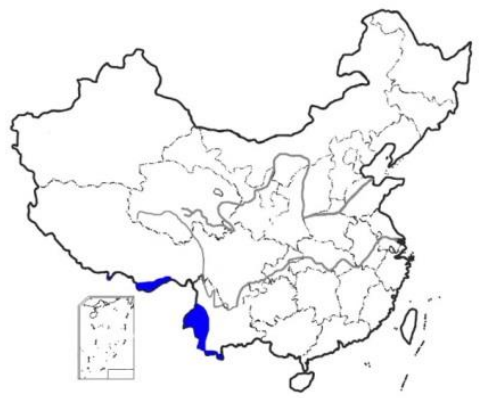

Red-headed Vulture

(Sarcogyps calvus) 


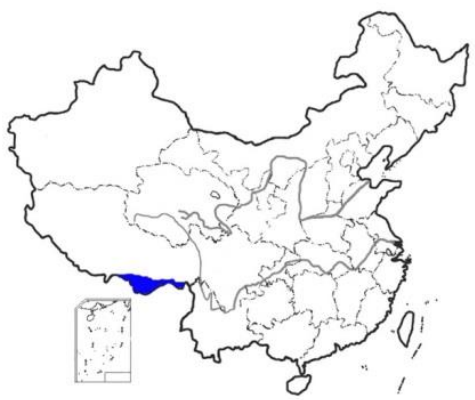

Slender-billed Vulture (Gyps tenuirostris)

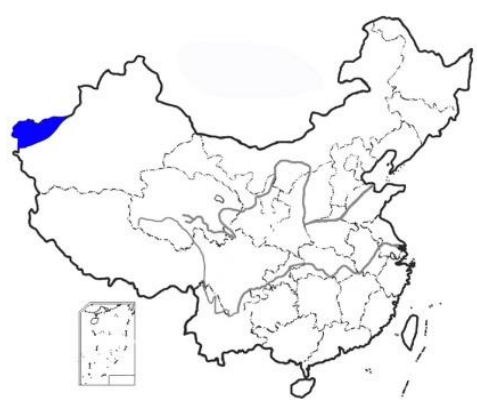

Egyptian Vulture (Neophron percnopterus)

Figure 1: Distribution maps of the eight vulture species in China

\section{Domestic Research Status}

In China there have been few studies on large carrion-eating raptors (Ye 1991), especially in relation to reproductive biology and population ecology. Published reports are few and deficient in detail and the research literature is limited. In conclusion, little is known about the breeding biology, habitat preferences or behaviour and ecology of China's vultures, for a number of reasons. Firstly, harsh environmental conditions and in particular high altitude, cold climate settings is a significant obstacle to research work. Secondly, the relevant areas are usually geographically remote, which adds to time, labour and logistical costs; many areas are inaccessible. Finally, there is limited funding for vulture research in addition to current government priorities being directed in other areas.

Vultures in China are sustained mainly by feeding on livestock carcasses in the region. As obligate scavengers they occupy an important ecological niche by contributing to carcass removal and nutrient recycling. A particular role performed by vultures relates to the centuries-old sky burial tradition, which is followed by nearly five million Tibetan people (Figure 2). 
Sky burial is how Tibetan culture treats its dead. At sky burial sites, human bodies are typically cut up, with bones broken into fragments by burial priests, and these are consumed entirely by griffons and other scavengers. A total of 1,200 sky burial sites are distributed over the Tibetan plateau. Local Buddhist people believe that the vultures take the soul of the dead person to heaven. Because of this, local people value and protect vultures.

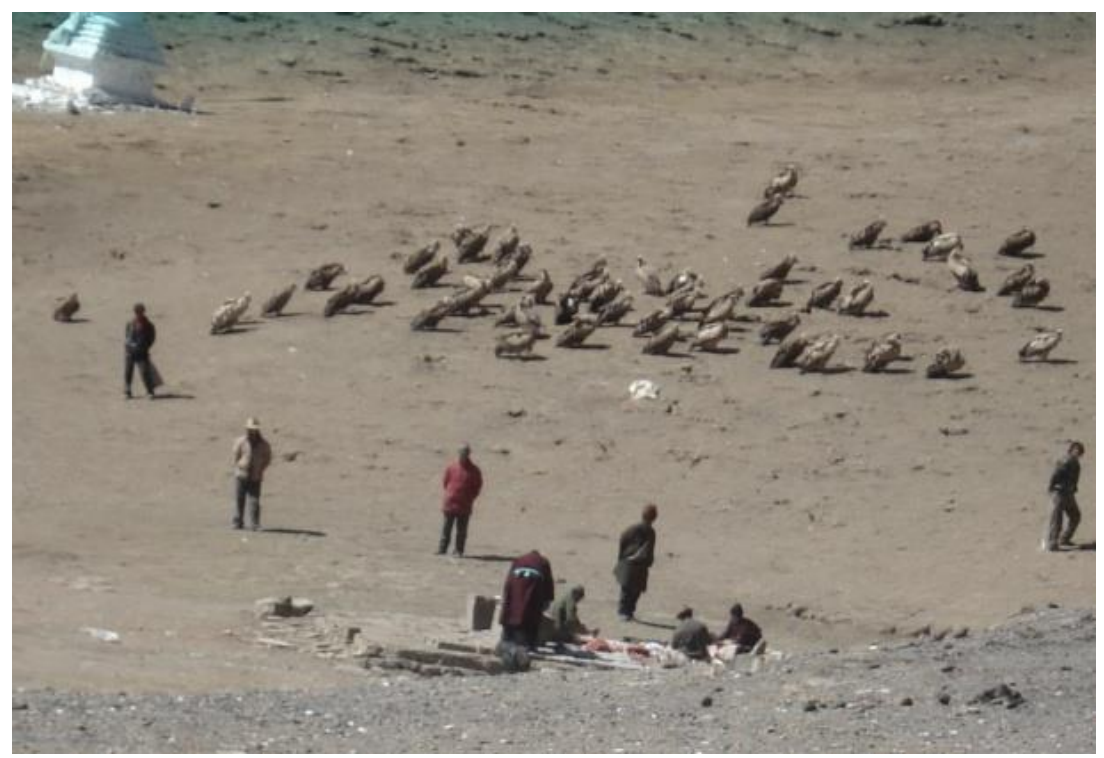

Figure 2: Sky burial and Himalayan Griffon in Tibet

\section{Potential Threats to Vultures in China}

Today, vultures face many survival problems in China. Poisoning, wind power stations, poaching, capture, specimen trade, highway construction and the use of vulture parts for cultural purposes are all threats. In particular, due to development in the western regions of the country, vultures in China face a series of threats. Here we describe some of these threats in greater detail. 


\section{Poisoning.}

Traditional agricultural practices that use limited pesticides are practiced throughout the plateau areas of China. However, in the northeast in western Sichuan, Northern Qinghai, and Southern Gansu, pesticides are commonly used for controlling pika (Ochotona spp.), which could cause secondary poisoning of vultures (Hernández and Margalida 2008). Some farmers, aiming to control other scavengers and predators such as wolves and wild dogs, lay out deliberately poisoned carcasses, and vultures become the unintended victims (Figure 3 ). In such cases, one poisoned carcass can kill a large number of vultures. At one sky burial site, we were told by local people that about 100 vultures were found dead after feeding on a human carcass (Jin and Yu 2004). This matter caused quite a shock among the local community, and as a result, sky burials were not permitted for people who died of toxicosis or infectious diseases, in an attempt to prevent poisoning of vultures.

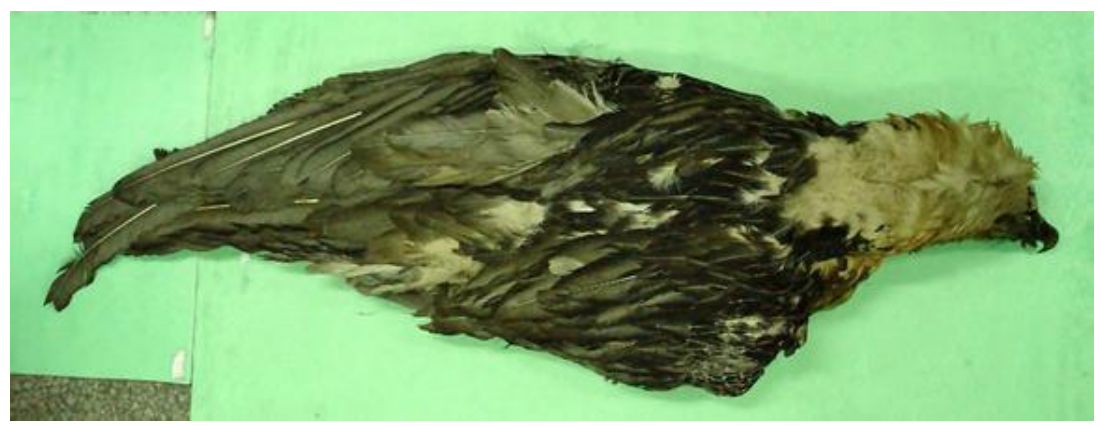

Figure 3: A poisoned Bearded Vulture

The population collapse of three species of Gyps vultures (Oriental White-backed Vulture Gyps bengalensis, Long-billed Vulture Gyps indicus and Slender-billed Vulture Gyps tenuirostris) due to the use of veterinary diclofenac in South Asia (Oaks et al. 2004, Pain et al. 2003) led to these species being reclassified as Critically Endangered and diclofenac being banned in the region. However, the surviving vultures remain under threat due to residual diclofenac use (Das et al. 2011) as well as other veterinary drugs. Currently, it is unknown if diclofenac is affecting populations of vultures and other scavenging birds 
in China, but given the ubiquitous nature of the drug prior to the ban, there is a likely risk. Vultures in China have a geographic distribution that overlaps with that of the three Gyps species in south Asia, and they share similar foraging behaviors. We consider that the vultures in China are highly likely to be subject to diclofenac poisoning, and this situation requires urgent investigation.

\section{The threat of the power grid.}

At present, the northwest power grid and Tibet power grid are spreading into the western areas of China. Additionally, based on the abundant wind resources in western China, a large number of wind farms have been established. The largest wind farm in China is located in Xinjiang (Figure 4). This brings negative effects to the survival of raptors. For example, the design of the grid structure is often unsafe and electrical wiring is often bare, which lacks any measure of protection for birds. According to investigations, about $20 \%$ raptors are under the threat of electrocution in the west, the number of dead raptors as high as 1.36 per kilometre (Mei \& Ma 2008). We were surprised to find up to five dead raptors under some electricity poles. These mortalities not only affect the survival of local raptor populations, but also the safe operation of the transmission lines (Mei \& Ma 2008).

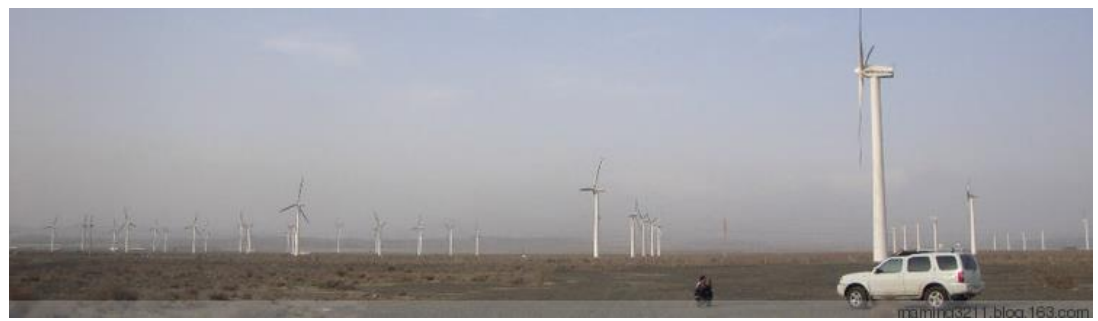

Figure 4: The wind power station in west China

\section{Specimen making and trading.}

People have found that vultures have a special form and a high ornamental value since the 1990s. Vulture feathers also have a high value, so some people kill vultures to make ornaments, which are a deformed fashion decoration, or trap the vultures for their plumage. Today, 
more and more people are addicted to these fetishes. Specimen trading for a wide range of uses including herbariums, museums, schools, research, individual collectors and the market for animal parts means that prices for vulture parts remain very high. For example, a good vulture specimen can be worth as much as 12,000 Yuan [ $\$ 2,000$ US] or more, and this high value contributes to demand. In addition, the Tibetan and Tajik people make flutes with vulture bones to play music (Figure 5), which is part of their traditional culture (MaMing et al. 2014). Flutes made from vulture wing bones are very expensive; prices in Xinjiang can exceed 10,000 Yuan $\quad[\sim \$ 1,700 \quad$ US $]$, which undoubtedly stimulates harvesting of vultures from the wild.

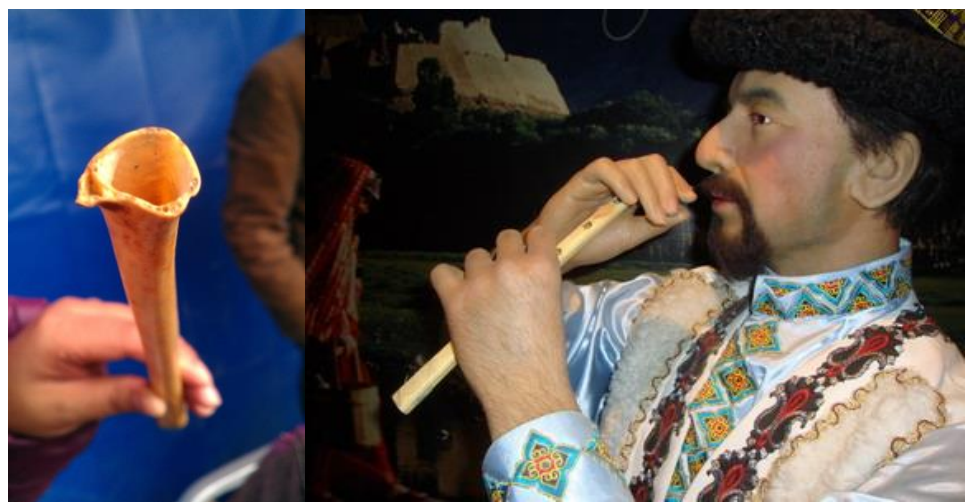

Figure 5: The specimen and vulture bone flute in China

\section{Food Shortage.}

Farm management has gradually improved in the west of China; death rates in grazing cattle have greatly decreased due to improved disease control and prevention, reducing food for vultures. Local Islamic people do not eat animals that have died naturally, and in the past this helped vultures, but since the price of meat has increased sharply, many animals that died naturally have been collected by local people (Tashi and Zhou 2009). Some Han people with no religious beliefs process these dead bodies into dry spicy meat (such as sausage, bacon, dumplings, jerky, dried meat, etc.) for sale illegally. Both activities reduce food for vultures. 
The human population has expanded very rapidly in the last decade and with it there has been a sharp increase in outdoor tourist activities that can lead to disturbance of breeding vultures. There are other reasons for reduced food supply for vultures. For example, in some areas deceased humans are buried or cremated instead of going to sky burial, whilst declining populations of Wolves (Canis lupus), Dholes (Cuon alpinus) and Snow Leopards (Uncia uncia) have also affected the food supply of vultures (Ma et al. 2014) in the form of reduced carrion from predator kills (Figure 6).
Between August-October 2012 and March-October 2013, we spent more than 90 days in the field in central Tien Shan, and we found some chicks still in the nest in September and October. This is a very unusual phenomenon. We speculate that the food shortages is a reason why they are still in the nest (Ma et al. 2013, Liu et al. 2013, Clements et al. 2013). At the same time, in the western region, we found some vultures breeding earlier than normal, which may be a strategy response to climate change, different land-use practices and food changes (Houston 1990, Murn and Anderson 2008).

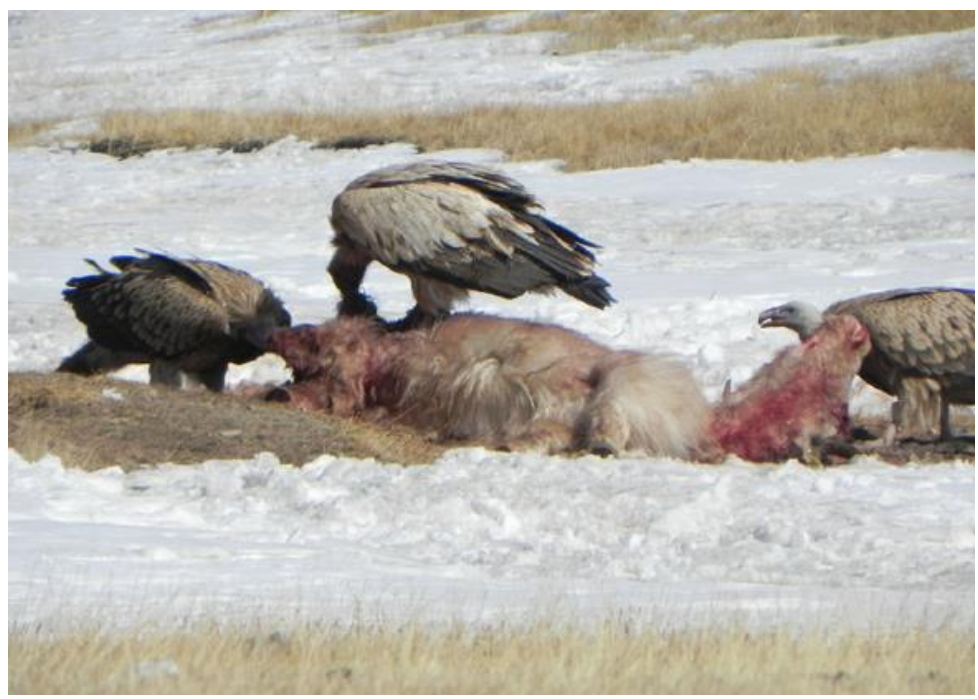

Figure 6: Himalayan Griffons eating a dead yak 


\section{Demand by zoos.}

In order to attract tourists and make money, some local zoos and other venues capture wild vultures for public display. Visitors pay money to take pictures and pose with the birds (Figure 7). At a zoo in Ningbo, it was observed that in order to celebrate the construction of a new enclosure, nine Himalayan Griffons (Figure 8) were put on display. The fate of these birds is unknown, but it is clear they were captured from the wild as there is no breeding of this species in zoos. Further, due to inadequate management, it is likely that these birds will be dead before too long, thus requiring that more wild birds are captured. As a result, capturing vultures from the wild is unlikely to end, which will continue to have a detrimental impact on wild populations.

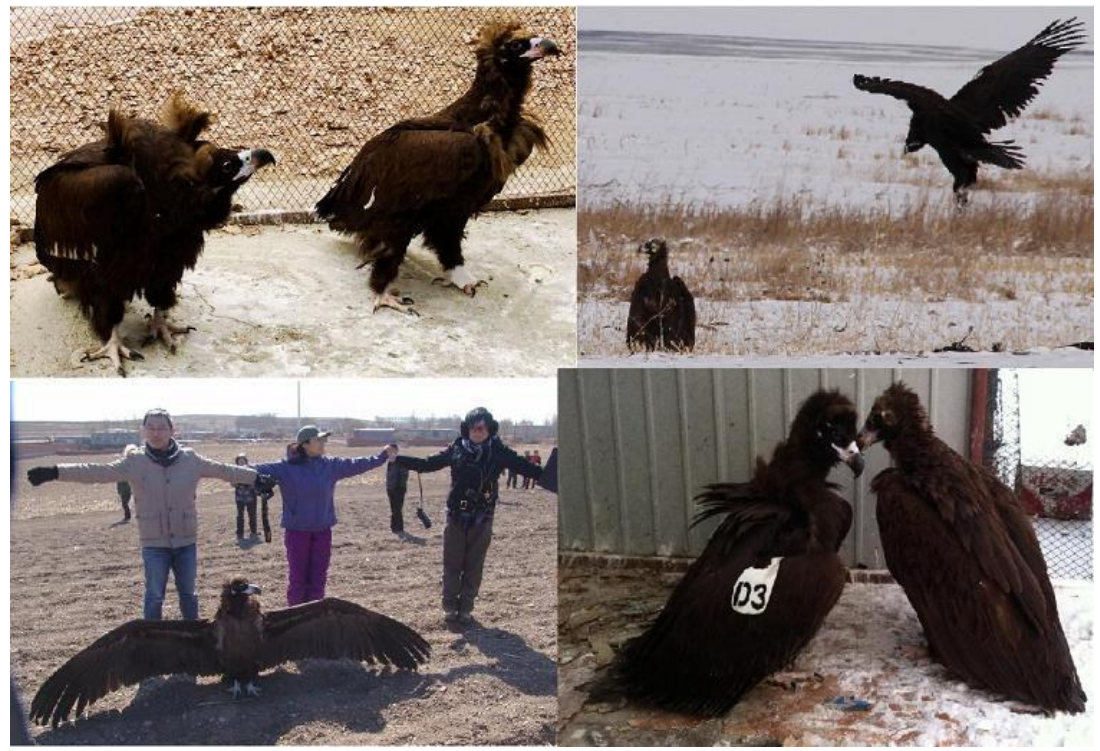

Figure 7: These Cinereous Vultures were caught for sport or entertainment 


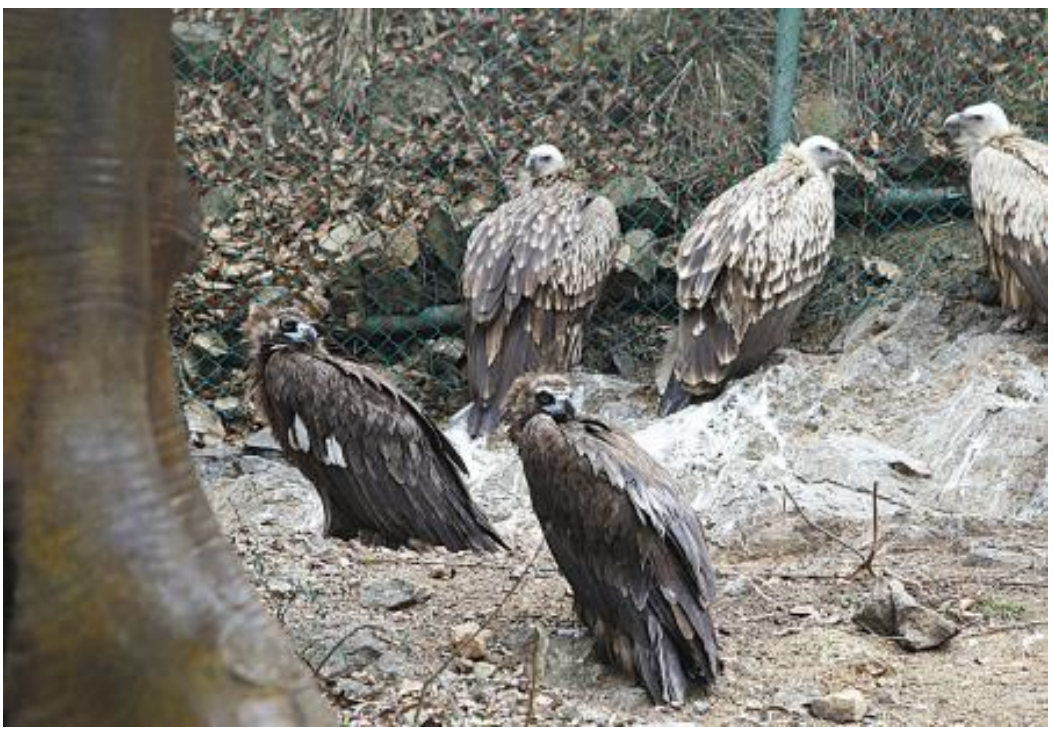

Figure 8: Himalayan Griffons and Cinereous Vultures in Ningbo Zoo

\section{Medicinal value.}

The theory of traditional Chinese medicine considers that vultures, along with other birds of prey, have many important medical functions, especially some unique curative effects. For example, feather, bone, meat, beak, claw, faeces and internal organs such as craw, gizzard or stomach have all been used for traditional medicine since ancient times (Li 1981, Luo 2003, Leung 2006). This leads to vultures being caught and sold for medicinal components (Fauna of Medicinal Animal in China 1979, Li 1981, Leung 2006). Some Chinese herbal medicine shops sell desiccated vulture parts - heads, talons, feathers, eyes, beaks and hearts for traditional medicine or fetishes (Figure 9). In some areas, we were surprised to find vulture meat was traded (Koenig 2006). These uses stimulate people to kill more vultures. 

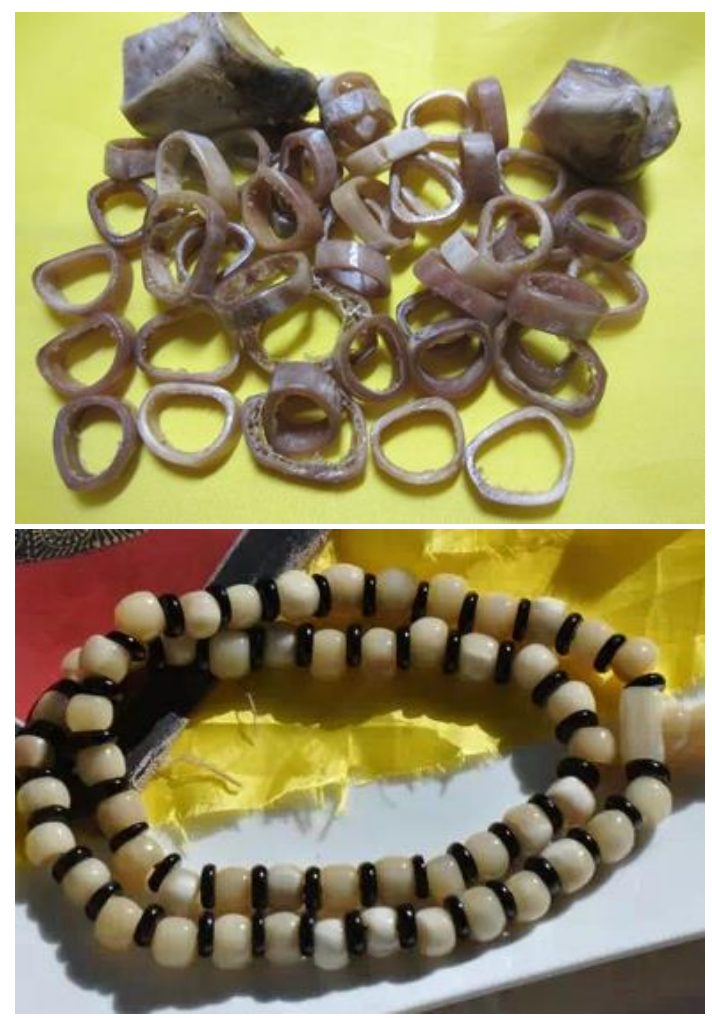

Figure 9: The bones from a Cinereous Vulture for sale in a shop

\section{Illegal hunting.}

Illegal hunting in the western region and central mountains in China is very widespread. According to a report, at noon on May 25, 2003, a Cinereous Vulture was illegally shot by a hunter in the Yibin County. The head and foot was badly hurt, and the bird was taken to a local zoo in a critical condition. From the vulture head and leg we removed two fragment of the shots by emergency operation (Figure 10). Illegal hunting is also used to obtain birds for sale (Figure 11) and to take live samples for medicinal purposes. The value of such commodities is high and there is a ready market for them. These factors encourage criminals to take risks to capture raptors for sale. 


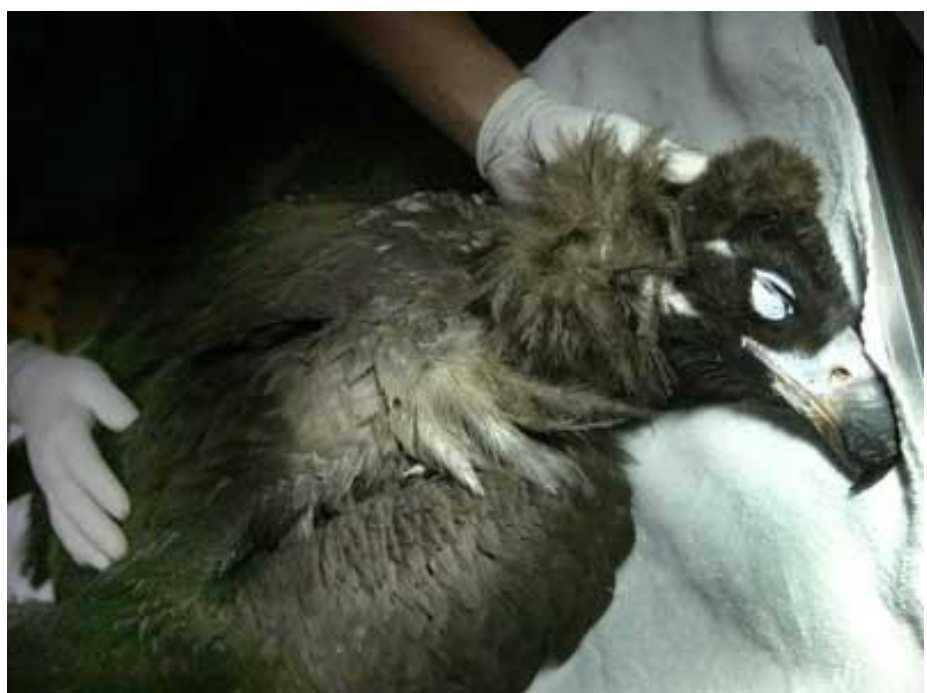

Figure 10: Rescued injured Cinereous Vulture

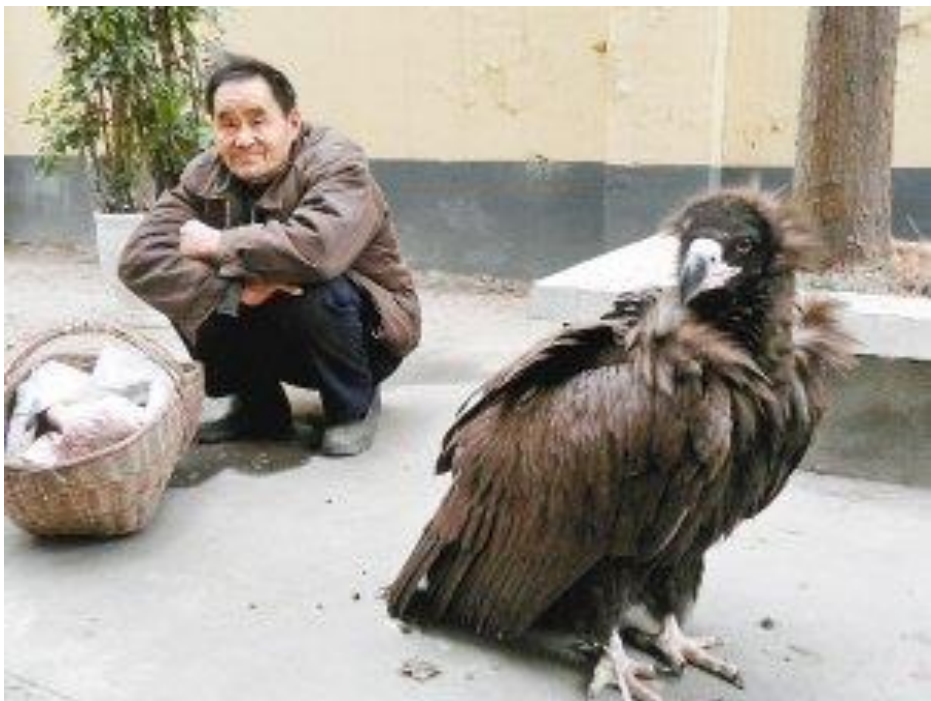

Figure 11: Cinereous Vulture for sale in Yibin 


\section{Discussion}

In recent years, the western regions of China have seen development in the form of mining operations, roads and a growing human population. This has damaged local environments, including the habitat of raptors, and has been a great threat to vulture populations.

At present, there have been few studies of the large carrion-eating raptors in China (Ye 1991) and published reports are few and limited in detail. Many statistics about vultures released by the relevant departments in China are inaccurate, so there is a lack of baseline knowledge about vultures, which hinders the formulation of appropriate laws and essential conservation measures. These species are still poorly understood in China, but they are facing a dangerous situation. If vultures continue to decline, the ecological and economic implications are hard to determine at present, but ecological systems will undoubtedly be affected negatively. Additionally, the loss of vultures has serious cultural and religious implications (Satheesan 1998), and potentially for other wildlife and for human health. Further research is urgently required. Vultures, as obligate scavengers, not only play a significant role in maintaining ecosystem function, they are highly respected in Buddhist culture and have a significant role in terms of cultural unity and social stability.

The threats to vultures across the world are numerous (Ledger and Annegarn 1981, Cunningham 1990, Camiña and Montelío 2006, McKie 2007, Naidoo et al. 2009, Ogada 2014, Saidu \& Buij, 2013, Williams et al. 2014) and similar threats are likely to be occurring in China, but have not been evaluated fully. We recommend that a detailed evaluation of these threats takes place, and in particular quantifying their impact on vulture populations in China.

\section{Acknowledgements}

This research was supported by the National Natural Science Foundation of China (31572292, 31272291, 30970340). Field workers included Li Bo, Liu Zheqing, Dao Caiwujiap, Shan Jiap, Xing Rui, Luo Biao, Wang Yaotian, Chen Xiting, Li Weidong, Shi Zhu, Jirige Lite, Ding Peng, Te Lai, Zhang Tong, Zhao Xumao, Xu Feng, Sun Dahuan (the Xinjiang

Bird-watching Society), HF Cheung (the Hong Kong Bird Watching Society), Ablimit Abdukadir, Lin Xuanlong, 
MardanTurghan, Shi Lei, Ba Tai, Cai Wenjun, Maimaitiming Aizijiang, Dai, Yang Xiaomin, Huang Yahui, Ma Yao, Gao Xiaoqing, Ting Zhou Jiang Yingxin, Jiang Mingyi, Xiang etc.

Keywords: Vultures, population size, status, threatened, China

\section{References}

BirdLife International. 2014. Species factsheets: Gypaetus barbatus, Gyps bengalensis, Gyps himalayensis, Gyps fulvus, Aegypius monachus, Sarcogyps calvus, Gyps tenuirostris, Neophron percnopterus. Downloaded from http://www.birdlife.org on 2/5/2014.

Camiña, A. and Montelío, E. 2006. Griffon vulture Gyps fulvus food shortages in the Ebro Valley (NE Spain) caused by regulations against bovine spongiform encephalopathy (BSE). Acta Ornithologica 41: 7-13.

Clements, T., Gilbert, M., Rainey, H. J., Cuthbert, R., Eames, J. C., Bunnat, P., Teak, S., Chansocheat, S., and Setha, T. 2013. Vultures in Cambodia: population, threats and conservation. Bird Conservation International 23: 7-24.

Cunningham, A. B. 1990. Vultures and the trade in traditional medicine. Vulture news 24: 3-10.

Das, D., Cuthbert, R. J., Jakati, R. D. 2011. Diclofenac is toxic to the Himalayan Vulture Gyps himalayensis. Bird Conservation International 21: $72-75$.

Di, Z, Y. 2003. The giant among the birds of prey. Man and the Biosphere 8: 36-41. (In Chinese).

Fauna of Medicinal Animal in China. 1979. Tianjin: Tianjin Science and Technology Press, Tianjin, China. (In Chinese).

Green, R. E., Newton, I. A. N., Shultz, S., Cunningham, A., Gilbert, M., Pain, D. J., Prakash, V. 2004. Diclofenac poisoning as a cause of vulture population declines across the Indian subcontinent. Journal of Applied Ecology 41: 793-800.

Gu, B. Y., Su, H. L. \& Caiba, Z. X. 1994. The preliminary research of Lammergeier breeding in the eastern Tibet. Tibet's Science \& Technology 4: 58-62. 
Guo, H. \& Ma, M. 2012. The Egyptian Vulture (Neophron percnopterus): record of a new bird in China. Chinese Birds 3: 238-239.

Hernández, M. \& Margalida, A. 2008. Pesticide abuse in Europe: effects on the Cinereous vulture (Aegypius monachus) population in Spain. Ecotoxicology 17: 264-272.

Houston, D. C. 1990. A change in the breeding season of Rüppell's Griffon Vultures Gyps rueppellii in the Serengeti in response to changes in ungulate populations. Ibis 132: 36-41.

IUCN Red List of Threatened Species, 2013 (http://www.iucnredlist.org/).

Jin, Y. and Yu, Q. 2004. Vultures in the plateau. Man \& Nature 4: 74-79. (In Chinese).

Kenny, D., Batbayar, N., Tsolmonjav, P., Willis, M.J., Azua, J. \& Reading, R. 2008. Dispersal of Eurasian Black Vulture Aegypius monachus fledglings from the IkhNart Nature Reserve, Mongolia. Vulture News 59:13-19.

Koenig, R. 2006. Vulture research soars as the scavengers' numbers decline. Science 312: 1591-1592.

Ledger, J. A. and Annegarn, H. J. 1981. Electrocution hazards to the Cape Vulture (Gyps coprotheres) in South Africa. Biological Conservation 20: 15-24.

Leung, A. Y. 2006. Traditional toxicity documentation of Chinese materia medica-An overview. Toxicologic Pathology 34: 319-326.

Li, S. Z (Ming Dynasty). 1981. Bencao Gangmu (Compendium of materia medica). People's Health Publishing House, Beijing, China. (In Chinese).

Liu, C., Huo, Z. P. \& Yu, X. P. 2013. Population and conservation status of the Himalayan Griffon (Gyps himalayensis) at the Drigung Thel Monastery, Tibet, China. Chinese Birds 4:328-331.

Lu, X., Ke, D. H. \& Zeng, X. H. 2009. Status, ecology and conservation of the Himalayan Griffon Gyps himalayensis (Aves, Accipitridae) in the Tibetan Plateau. Ambio 38: 166-173.

Luo, X. W. 2003. Bencao Gangmu (Compendium of Materia Medica). Foreign Languages Press, Beijing, China.

Ma, M. 2011. A checklist on the distribution of the birds in Xinjiang. Science Press, Beijing, China.

Ma, M., Caiwujiap, D. \& Shan, J. 2014. Study of the reproductive behavior of Himalayan Vulture (Gyps himalayensis) by mini camera-traps in the Tianshan Mountains. Chinese Journal of Wildlife 35: 414-419. 
Ma, M., Caiwujiap, D. \& Xu, G.H. 2013. Why are juvenile Himalayan Vultures Gyps himalayensis in the Xinjiang Tien Shan still at the nest in October? Birding ASIA 20: 84-92.

MaMing R, Zhao X. M., Xu G. H., Caiwu J., Zhang T., Ding P. and Xu F. 2014. Raptor conservation and culture in the west of China. Ela Journal 3: 23-29.

McKie, R. 2007. Vulture numbers are cut to the bone - Extinction fears for a scavenger vital to preserving ecosystems. Vulture News 56: 95-96.

Mei, Y. \& Ma, M. 2008. The accident investigation of grid electric shock raptor to death in west China. Chinese Journal of Zoology 43: 114-117.

Murn, C. \& Anderson, M. D. 2008. Activity patterns of African White-backed Vultures Gyps africanus in relation to different land-use practices and food availability. Ostrich 79: 191-198.

Naidoo, V., Wolter, K., Cuthbert R., Duncan, N. 2009. Veterinary diclofenac threatens Africa's endangered vulture species. Regulatory toxicology and pharmacology 53: 205-208.

National Forestry Bureau. 2009. Resource survey on the key animals in China. China Forestry Publishing House, Beijing, China. (In Chinese).

Oaks, J.L., Gilbert, M., Virani, M. Z., Watson, R. T. \& Meteyer, C. U. 2004. Diclofenac residues as the cause of vulture population decline in Pakistan. Nature 427: 630-633.

Ogada, D. L. 2014. The power of poison: pesticide poisoning of Africa's wildlife. Annals of the New York Academy of Sciences 1322: 1-20.

Pain, D.J., Cunningham, A.A., Donald, P.F., Duckworth, J.W., Houston, D.C., Katzner, T., Parry-Jones, J., Poole, C., Prakash, V., Round, P. \& Timmins, R. 2003. Causes and effects of temporospatial declines of Gyps Vultures in Asia. Conservation Biology 17: 661-671.

Prakash, V., Bishwakarma, M. C., Chaudhary, A., Cuthbert, R., \& Dave, R. 2012. The population decline of Gyps Vultures in India and Nepal has slowed since veterinary use of diclofenac was banned. PLoS ONE 7(11): e49118.

Saidu, Y. \& Buij, R. 2013. Traditional medicine trade in vulture parts in northern Nigeria. Vulture News 65: 4-14.

Satheesan, S.M. 1998. The role of vultures in the disposal of human corpses in India and Tibet. Vulture News 39: 32-33. 
Tashi, S. \& Zhou, J. 2009. My Himalayan Vulture. Supported by Eu-China Programme (http://video.sina.com.cn/p/news/green/v/2011-0124/141461244735.html)

Wildlife Protection Law of the People's Republic of China. 2004. (http://www.gov.cn/fwxx/bw/lyj/content_396083.htm).

Williams, V. L., Cunningham, A. B., Kemp, A. C. \& Bruyns, R. K. 2014. Risks to birds traded for African traditional medicine: A quantitative assessment. PloS one 9(8): e105397.

Xu, W.S. 1995. China's birds of prey. China Forestry Publishing, Beijing, China.

Ye, X.T. 1991. Distribution and status of the Cinereous Vulture Aegypius monachus in China. Birds of Prey Bulletin 4: 51-56.

Zhang, F.Y. \& Yang, R.L. 1980. The Lammergeyer in the southern Gansu. Acta Zoologica Sinica 26: 86-90.

Zheng, G.M. 2011. A checklist on the classification and distribution of the birds of China. Science Press, Beijing, China. 